\title{
Quantifying and monetizing potential climate change policy impacts on terrestrial ecosystem carbon storage and wildfires in the United States
}

\author{
David Mills • Russell Jones • Karen Carney • \\ Alexis St. Juliana • Richard Ready • Allison Crimmins • \\ Jeremy Martinich • Kate Shouse • Benjamin DeAngelo • \\ Erwan Monier
}

Received: 26 February 2013 / Accepted: 26 March 2014 /Published online: 24 April 2014

C The Author(s) 2014. This article is published with open access at Springerlink.com

\begin{abstract}
This paper develops and applies methods to quantify and monetize projected impacts on terrestrial ecosystem carbon storage and areas burned by wildfires in the contiguous United States under scenarios with and without global greenhouse gas mitigation. The MC1 dynamic global vegetation model is used to develop physical impact projections using three climate models that project a range of future conditions. We also investigate the sensitivity of future climates to different initial conditions of the climate model. Our analysis reveals that mitigation, where global radiative forcing is stabilized at $3.7 \mathrm{~W} / \mathrm{m}^{2}$ in 2100 , would consistently reduce areas burned from 2001 to 2100 by tens of millions of hectares. Monetized, these impacts are equivalent to potentially avoiding billions of dollars (discounted) in wildfire response costs. Impacts to terrestrial ecosystem carbon storage are less uniform, but changes are on the order of billions of tons over this time period. The equivalent social value of these
\end{abstract}

This article is part of a Special Issue on "A Multi-Model Framework to Achieve Consistent Evaluation of Climate Change Impacts in the United States" edited by Jeremy Martinich, John Reilly, Stephanie Waldhoff, Marcus Sarofim, and James McFarland.

Electronic supplementary material The online version of this article (doi:10.1007/s10584-014-1118-z) contains supplementary material, which is available to authorized users.

D. Mills $(\bowtie) \cdot$ R. Jones $\cdot$ K. Carney $\cdot$ A. St. Juliana

Stratus Consulting Inc., 1881 Ninth Street, Suite 201, Boulder, CO 80302, USA

e-mail: dmills@stratusconsulting.com

R. Jones

e-mail: RJones@stratusconsulting.com

K. Carney

e-mail: KCarney@stratusconsulting.com

A. St. Juliana

e-mail: AStJuliana@stratusconsulting.com

R. Ready

Penn State University, 417 Old Main, University Park, PA 16802, USA

e-mail: rready@psu.edu 
changes in carbon storage ranges from hundreds of billions to trillions of dollars (discounted). The magnitude of these results highlights their importance when evaluating climate policy options. However, our results also show national outcomes are driven by a few regions and results are not uniform across regions, time periods, or models. Differences in the results based on the modeling approach and across initializing conditions also raise important questions about how variability in projected climates is accounted for, especially when considering impacts where extreme or threshold conditions are important.

\section{Introduction}

Terrestrial ecosystems provide valuable goods and services in the United States (U.S.) such as timber, recreation, wildlife habitat, flooding and erosion management, and clean drinking water. These ecosystems also play an important role in the global carbon budget by storing up to four times more carbon than the atmosphere (Lal 2004). Forests in the U.S. currently account for a net gain in carbon storage and absorb the equivalent of $16 \%$ of all the carbon dioxide $\left(\mathrm{CO}_{2}\right)$ annually emitted by U.S. fossil fuel combustion, capturing and storing more than 228 million tons of carbon per year (USEPA 2013). Wildfires are a major force shaping terrestrial ecosystems, affecting the types of services the systems can provide and their carbon storage capacity in the short- and long-term. Climate change will affect terrestrial ecosystem carbon storage and wildfire incidence in the U.S. (USDA 2012). This raises important questions regarding the future role of terrestrial ecosystems in greenhouse gas (GHG) emission mitigation policies when considering potential climate change impacts.

This study's main goal was to develop and apply methods to quantify and monetize these climate-sensitive impacts for better integration in policy analyses. To achieve this goal, we used MC1 (Oregon State University 2011), a dynamic global vegetation model (DGVM), to project climate change impacts on terrestrial ecosystem carbon storage and area burned by wildfires in the contiguous U.S. for the 2001 through 2100 period. We assessed the sensitivity of impacts to (1) the GHG emission scenario, (2) the methods used to project future climate (i.e., general circulation model, or GCM, and pattern-scaled projections), and (3) natural climate variability by altering initializing conditions of a climate model. Our analysis and discussion focus on the implications of various methodological and analytical choices on the integration of such impacts into policy analysis.

While previous studies have examined the potential impacts of climate change on natural vegetation dynamics in the U.S. (e.g., Daly et al. 2000; Bachelet et al. 2004; Lenihan et al.

A. Crimmins $\cdot$ J. Martinich $\cdot$ K. Shouse $\cdot$ B. DeAngelo

U.S. Environmental Protection Agency, Climate Change Division, Ariel Rios Building, 1200 Pennsylvania Avenue, NW, Washington, DC 20460, USA

A. Crimmins

e-mail: crimmins.allison@epa.gov

J. Martinich

e-mail: Martinich.Jeremy@epa.gov

K. Shouse

e-mail: Shouse.Kate@epa.gov

B. DeAngelo

e-mail: deangelo.ben@epa.gov

E. Monier

Massachusetts Institute of Technology, 77 Massachusetts Avenue, Cambridge, MA 02139, USA

e-mail: emonier@mit.edu 
2008; Shaw et al. 2009; Spracklen et al. 2009; NRC 2011), ours is the first national analysis conducted in concert with a wide range of other sectoral impact analyses (Waldhoff et al. 2014, this issue). Our approach, which utilizes the same emission scenarios and climate projections as the other studies in this issue, allows for a direct comparison of the magnitude and nature of ecological impacts across sectors. In addition, our effort to monetize some of the key impacts associated with changes in natural vegetation and area burned by wildfire at a national scale are unique. As in the larger integrated project, this analysis does not examine the effects of mitigation actions specific to the studied sector (i.e., carbon sequestration activities); rather, GHG mitigation scenarios are assumed to occur as a result of mitigation actions at the global scale.

\section{Emission scenarios and climate projections}

Detailed descriptions of the emission scenarios used in this analysis, along with a comparison to other emission scenarios (e.g., the Representative Concentration Pathways or RCPs) and global climate projections, are provided elsewhere in this special issue (Paltsev et al. 2013; Waldhoff et al. 2014; both this issue). In short, two emission scenarios were developed using the emissions component of the Massachusetts Institute of Technology's Integrated Global System Model (IGSM): a reference (REF) scenario with unconstrained emissions and a total radiative forcing of $10 \mathrm{~W} / \mathrm{m}^{2}$ by 2100 , and a stabilization scenario with a total radiative forcing of $3.7 \mathrm{~W} / \mathrm{m}^{2}$ by 2100 (POL3.7). In addition, all climate simulations used in this analysis assume a climate sensitivity of $3^{\circ} \mathrm{C} .1$

Using these scenarios, future climate projections were developed with the IGSM using two different downscaling methods. First, the IGSM Community Atmospheric Model (CAM) framework (Monier et al. 2013) links the IGSM to the National Center for Atmospheric Research CAM version 3. Because CAM is a three-dimensional atmosphere model, the IGSMCAM simulates not only changes in mean climate, but also realistically simulates synoptic to decadal variability as well as extreme events (e.g., from heat waves to multi-year drought events). As noted in Monier et al. (2014, this issue), IGSM-CAM was run for each emission scenario under different initial conditions providing several equally plausible future climates.

Since IGSM-CAM only considers one GCM, a pattern-scaling approach was also used to capture a wider range of regional patterns of change, especially for precipitation (see Monier et al. 2014, this issue, for methodological details). Pattern scaling generally enables the development of projections of mean climate conditions from a range of GCMs without developing new model runs. Two GCMs were chosen with very different patterns of change over the U.S.: the Model for Interdisciplinary Research on Climate (MIROC3.2-medres) projects drying and a strong warming, and the Community Climate System Model (CCSM3.0) projects more moisture and less warming than MIROC. Monier et al. (2014, this issue) describe the details of the IGSM pattern-scaling method and provide a comparison between the two downscaling methods. Online Resource 1 summarizes the primary modelscenario combinations we evaluated. ${ }^{2}$

\footnotetext{
${ }^{1}$ As described in Paltsev et al. (2013, this issue), the global mean temperature increases under the POL3.7 and REF (climate sensitivity of $3{ }^{\circ} \mathrm{C}$ ) scenarios are $1^{\circ}$ and $6^{\circ} \mathrm{C}$, respectively, by 2100 .

${ }^{2}$ Results from these models are distinguished from the IGSM-CAM results by appending the model name to the POL3.7 and REF identifiers. For example, REF scenario results from the MIROC model will be noted as REFMIROC (see Online Resource 1).
} 
The pattern-scaling approach tends to suppress year-to-year variability and thus cannot realistically simulate changes in extreme events. In contrast, the IGSM-CAM realistically simulates natural variability and, as a result, can simulate future changes in extreme events. Online Resource 2 provides more details on the initial condition perturbation and on the differences in natural variability simulated by the two downscaling methods.

\section{Methods}

\subsection{MC1 use and overview}

We used the MC1 DGVM to project area burned by wildfires and terrestrial ecosystem carbon storage under future climates in the contiguous U.S. MC1 is a spatially explicit gridded model that dynamically integrates the output from three sub-models: biogeography, biogeochemistry, and fire. It has been used to assess projected climate change impacts on the distribution of potential natural vegetation, ecosystem productivity, carbon storage, and fire dynamics at a variety of spatial scales across the U.S. (e.g., Daly et al. 2000; Bachelet et al. 2003, 2004; Lenihan et al. 2006, 2008) and thus is suitable for this assessment. The various components of the MC1 model have been explained in detail elsewhere (e.g., Bachelet et al. 2001, 2003), and thus are not discussed further here.

\section{2 $\mathrm{MC1}$ data preparation and operation}

We ran MC1 at a monthly time step covering the 2000-2100 modeling period at a cell resolution of $0.5^{\circ} \times 0.5^{\circ}$ (latitude/longitude, $\sim 1,600 \mathrm{~km}^{2}$ per cell). The climate inputs needed to run the model (average monthly maximum temperature or $\mathrm{T}_{\max }$, average monthly minimum temperature or $\mathrm{T}_{\mathrm{min}}$, average monthly precipitation or PPT, and average monthly vapor pressure or VPR) were derived from gridded data output from the aforementioned models (Monier et al. 2014, this issue). Executing MC1 also requires data inputs for elevation, soil bulk density, soil depth and texture (CBI 2011), and annual $\mathrm{CO}_{2}$ concentrations (Paltsev et al. 2013, this issue).

To process each climate variable, delta values by month and year were calculated that represented the difference (for temperature and VPR) or ratio (precipitation) between a future month and year and the modeled baseline developed from averaging values for the same month from the 1980-2009 period. For IGSM-CAM, the delta values were applied to monthly averages developed for the same baseline time period (1980-2009), assuming no climate change using observed climate data (i.e., PPT, $\mathrm{T}_{\max }, \mathrm{T}_{\min }$, and average monthly dew point) from PRISM (Parameter-elevation Regressions on Independent Slopes Model; PRISM Climate Group 2007). The resulting new values were then incorporated as the input data for $\mathrm{MC} 1{ }^{3}$ To better represent climatic inter-annual variability in pattern-scaled data, delta values were applied to observed monthly 1900-2000 historical data that were detrended to remove historical warming. Online Resource 4 details the processing of the climate inputs used for the IGSM pattern-scaled models.

\subsection{Projecting area burned by wildfires and terrestrial ecosystem carbon storage with MC1}

To simulate potential alternative future conditions, $\mathrm{MC1}$ was run for all model and emission scenarios. Because the $\mathrm{MC1}$ fire module was developed to simulate natural fire regimes, it

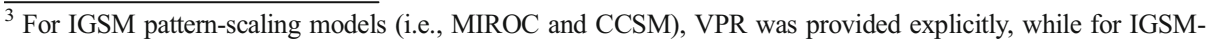
CAM, VPR was calculated from relative humidity in two steps (see Online Resource 3 for more details).
} 
tends to over-predict the total area burned in the U.S. when compared to observed data (Rogers et al. 2011). To better capture modern fire-suppression tactics and provide more realistic projections of wildfire extent and severity, we utilized MC1 and incorporated a new fire suppression rule developed by Rogers et al. (2011).

To account for the effect of $\mathrm{CO}_{2}$ fertilization on plant growth as atmospheric concentrations increase, we utilized the MC1's default beta factor of 0.8 . This factor increases the maximum potential productivity and reduces the moisture constraint on plant growth, generating about an $8 \%$ increase in net primary productivity at an atmospheric concentration of $550 \mathrm{ppm} \mathrm{CO}_{2}$ (Lenihan et al. 2008).

Cell-level model outputs provided by year for each scenario included the fraction of each cell burned and grams of carbon stored per square meter. These results were converted, using the area of MC1 cells, to billions of tons of carbon stored and area burned for each MC1 cell. Carbon storage estimates were further adjusted to account for available information on the extent of developed and agricultural lands over time (see Online Resource 5 for details). This adjustment reduces the values calculated based on the area of the $\mathrm{MC} 1$ cell to account for projected developed and agricultural areas. For example, if we project that $20 \%$ of a cell's area would be in some combination of developed or agricultural lands, the total values for carbon stored above- and below-ground calculated from the original $\mathrm{MC} 1$ output would be reduced by $20 \%$ before being summarized. This adjustment was not applied to fire output, where it is assumed that the percentage of vegetated, agricultural, and developed lands have the same potential to burn as other areas. The information used to define developed and agricultural areas is further explained in Online Resource 5.

To support the analysis of regional trends and to allow for the monetization of wildfire impacts incorporating observed spatial differences (see Section 3.4), the final adjusted results for carbon storage and area burned are summarized by Geographic Area Coordinate Center (GACC) fire region (GACC 2011; see Online Resource 6 for a map and description of GACC regions). For IGSM-CAM, this summarization process was completed using the climate data from each initializing condition. An average of the physical impacts by year across these conditions was then produced to generate a time series that equally weights the results from each initializing condition.

Online Resource 7 compares how our $\mathrm{MC1}$ results for historical periods compare with other published results in terms of vegetation distribution, carbon storage, and area burned. In general, our vegetation distribution and carbon storage results are consistent with other results. In contrast, our contemporary area burned results are smaller than other published results in a period that accounts for active fire suppression policies. However, differences in these results vary by vegetation type, and the specific measure of comparison used, a range based on minimum and maximum values, is sensitive to outlying values.

\subsection{Monetizing projected impacts}

We monetized projected impacts of area burned by wildfires and terrestrial ecosystem carbon storage using the methods described below.

\subsubsection{Wildfire response costs}

Regional average response costs per acre burned were calculated from National Wildfire Coordinating Group (NWCG) data on the area burned, origin, and total response cost for reported wildfires in the contiguous U.S. from 2002 to 2010 (NWCG 2011). These costs reflect the commitment of labor (e.g., fire crews) and equipment (e.g., helicopters, bulldozers) 
to fire-fighting efforts. Forestry/timber yield losses, post-fire habitat restoration costs, infrastructure protection costs, and associated human health impacts are not captured in these values. We evaluated data from all reported wildfires for the years 2002-2010 (NWCG 2011), including those with no reported response costs, and adjusted all values to their year 2005 equivalent using the Consumer Price Index (USDOL 2011). We used this regional average response costs per acre because it reflects evolving wildfire management practices. In particular, the expectation that not all future wildfires will receive active response activity is consistent with current practice. Online Resource 6 provides additional information on the estimation of these costs.

\subsubsection{Monetizing changes in terrestrial ecosystem carbon storage}

To monetize changes in ecosystem carbon storage, we used the U.S. government's updated social cost of carbon (SCC) values for the years 2010-2050 (U.S. Interagency Working Group on Social Cost of Carbon 2013). SCC values vary by year and discount rate. To value projected annual changes in carbon storage for the 2051-2100 period, we extrapolated these SCC values using a linear regression with an intercept. All SCC estimates were discounted back to the assumed policy year (2015) using the discount rates identified in the SCC $(2.5 \%$, $3 \%$, or $5 \%$ ). Additionally, original SCC values from the reported dollar year 2007 values were adjusted to their year 2005 equivalent using a price adjustment factor for consistency with other analyses in this issue. ${ }^{4}$ Online Resource 6 provides additional information on the source and use of the SCC values.

\section{Results}

Below, we discuss changes in future wildfire activity across the different emission scenarios and climate models (Section 4.1) and future changes in terrestrial ecosystem carbon storage (Section 4.2). In each section, biophysical impacts are presented at a national scale, summarized by region, and then monetized. The basic approach to defining the impacts of the POL3.7 GHG mitigation scenario for both wildfire and terrestrial ecosystem carbon storage relies on calculating an annual difference in projected physical impact values under the REF versus the POL3.7 scenario for a given year. These annual differences are then monetized, discounted, and aggregated. More details on historical vegetation, wildfire, and carbon dynamics are provided in Online Resources 7 and 11, with the latter also showing wildfire area burned at the regional level by decade.

\subsection{Future changes in area burned}

To estimate the benefit of the GHG mitigation scenario on area burned, POL3.7 scenario projections of burned areas are subtracted, by region, from similar REF projections. Thus, any reduction in area burned resulting from the POL3.7 GHG mitigation scenario produces a value greater than zero.

When using the projections for IGSM-CAM, MIROC, and CCSM, the benefits (area values $>0$ ) or damages (area values $<0$ ) of implementing climate change mitigation policy

\footnotetext{
${ }^{4}$ Carbon represents $12 / 44$ of each ton of $\mathrm{CO}_{2}$ based on the molecular weights of carbon-12 and oxygen-16. Therefore, SCC values are multiplied by the reciprocal of this ratio, 3.67, to reflect the greater proportion of carbon in each ton of carbon stored in terrestrial ecosystems.
} 
vary widely with annual variations reflecting millions of burned hectares (Fig. 1). For comparison, in recent extreme fire years, total area burned is on the order of 3.5 million hectares (National Interagency Fire Center 2013). The magnitude and variability of these results reflect characteristics of the model-specific climate projections and $\mathrm{MC1}$. Specifically, fire ignition occurs in $\mathrm{MC1}$ once threshold conditions for temperature and fuel moisture content are satisfied as ignition sources are assumed to be present. Online Resource 8 presents graphs depicting the POL3.7 impact on area burned from the different model projections nationally and by region.

As Online Resource 9 describes in detail for a single modeled cell, the IGSM-CAM method simulates realistic natural variability at the global and regional levels, as well as future changes in natural variability (changes in magnitude and frequency) (see Monier et al. 2014, this issue, for more detail). Compared to other GCMs, the IGSM-CAM projects a "wetter" future for most of the contiguous U.S., in addition to the underlying pattern of warming, which produces conditions that are generally more favorable to vegetation growth compared to today. However, as identified in Online Resource 9, this general pattern of growth is increasingly interrupted by extreme climatic conditions that drive massive burning. Online Resource 9 shows how an extremely wet period followed by an extremely hot/dry season can result in significant burning. In general, it is the repetition of this pattern that generates the large burned area projections for IGSM-CAM under both the POL3.7 and REF scenarios. Online Resource 10 provides additional context regarding the likely drivers of the wildfire results reported in this paper and a detailed comparison to findings reached in previous studies.

For IGSM-CAM, the average of results from the different initializing conditions show that implementing the POL3.7 scenario would reduce cumulative area burned between 2011 and 2100 by roughly 122 million hectares, relative to the REF scenario. The corresponding discounted (3\%) monetized estimate of reduced response costs over this period is $\$ 9.24$ billion (2005 dollars). While all IGSM-CAM initializations project a net reduction in wildfire

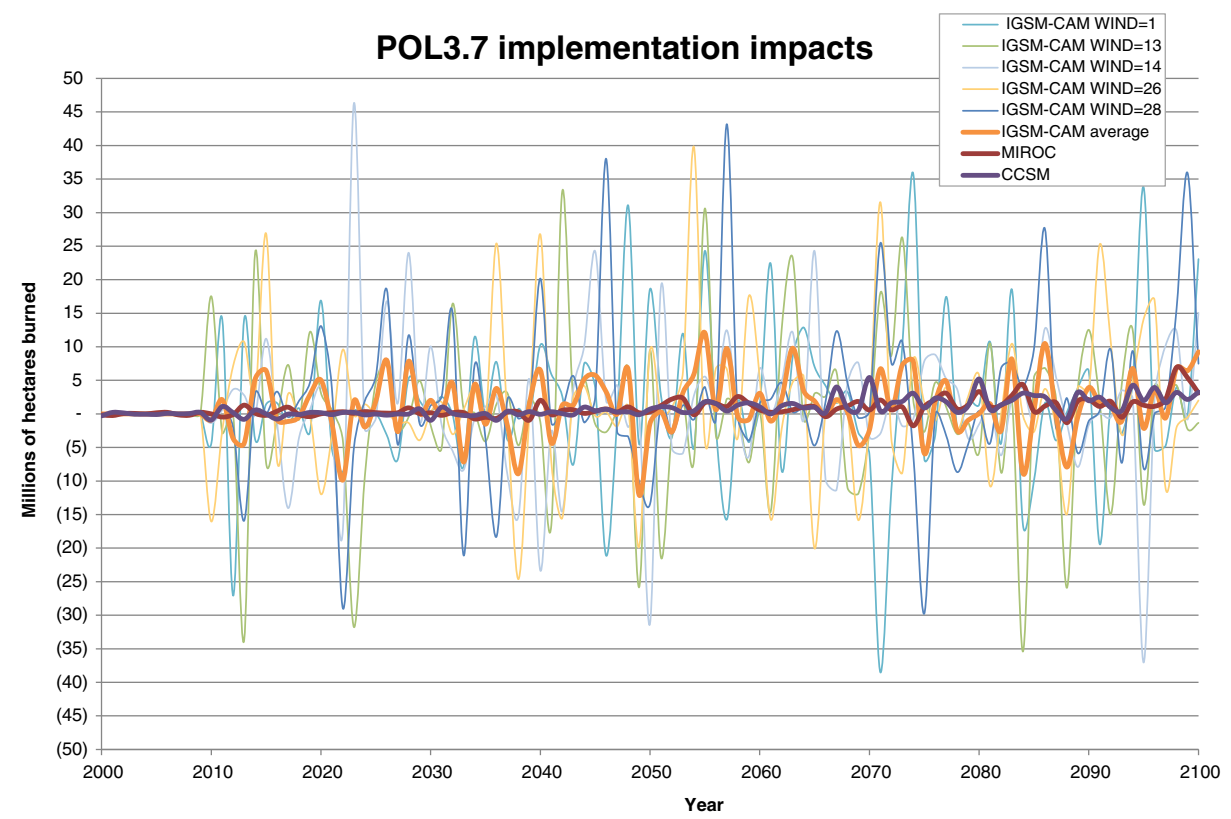

Fig. 1 Wildfire acreage burned using different GCM and emission scenarios 
area burned from implementing the POL3.7 emission controls, timing and magnitude of net impacts vary by initializing condition (Fig. 1). This is reflected in the standard deviation (SD) for the mean area (63 million hectares) and the SD for the mean-avoided wildfire response cost results ( $\$ 4.73$ billion, 2005 dollars). The MIROC and CCSM pattern-scaled models show benefits of 84 and 91 million burned hectares avoided with the POL3.7 implementation, with an associated cost reduction of $\$ 7.31$ and $\$ 7.77$ billion (2005 dollars), respectively.

While these national-level summaries suggest general agreement across the models, the regional results show considerable variation (see Online Resource 11). For example, projections for the Southwest region show reductions in the amount of burned area and response costs with implementing the POL3.7 emission controls across all models. In contrast, the same projected results for the Western Great Basin are quite different across models. The regional results also highlight how a limited number of regions dominate national results. For example, across models, the Southern Area region's results for area burned help determine national results (Online Resource 11).

The regional variability is also evident when examining a map of future burned area (Fig. 2). The IGSM-CAM projections consistently show burning affecting a larger region of the U.S. than the other two models, particularly in the South, Southeast, and Central region of the country.

While direct comparisons are difficult, variable but consistent increases in projections of the area burned by wildfires in future climates have been observed in other research. Online Resource 10 provides a comparison for recent studies in the contiguous U.S.

\subsection{Future changes in terrestrial ecosystem carbon storage}

Terrestrial ecosystem carbon storage impacts from implementing POL3.7 controls are quantified by subtracting REF from POL3.7 projections. As a result, additional carbon storage from POL3.7 implementation produces a value greater than zero.

Across models, the POL3.7 impact on terrestrial ecosystem carbon storage under the IGSM-CAM projections varies substantially over time. Figure 3 shows this variation with net benefits in some years and net damages (i.e., loss of carbon relative to the REF scenario) in others, often with rapid changes in sign and magnitude.

IGSM-CAM projections of carbon benefits/damages vary substantially among initializing conditions (Table 1). Across all initializing conditions, the IGSM-CAM results provide an average reduction in carbon storage in terrestrial ecosystems of 0.9 billion metric tons for the 2001-2100 period ( $\mathrm{SD}=39.2$ billion metric tons) from POL3.7 implementation. In some cases the timing of carbon storage changes, combined with discounting, results in net benefits even when there is a net reduction in carbon storage. Specifically, three of the five IGSM-CAM results show a reduction in net carbon storage while four of the five sets provide a monetized net benefit (discounted at $3 \%$ ) that averages roughly $\$ 1.66$ trillion dollars for the POL 3.7 implementation (2005USD, $\mathrm{SD}=\$ 2.71$ trillion). ${ }^{5}$

Variation in the sign and value of projected impacts from the POL3.7 scenario are also observed under both the MIROC and CCSM projections (Fig. 3, Table 1). The cumulative results from these projections bound the average of the IGSM-CAM results - a net reduction in carbon storage of 1.9 billion metric tons projected with CCSM and an increase in carbon storage of 60.5 billion metric tons with MIROC. These changes are associated with a reduction

\footnotetext{
${ }^{5}$ Online Resource 14 presents the impact on the monetized carbon storage results of using the alternative SCC series.
} 


\section{Business As Usual - 2080 (30-yr average)}

Policy Scenario - 2080 (30-yr average)
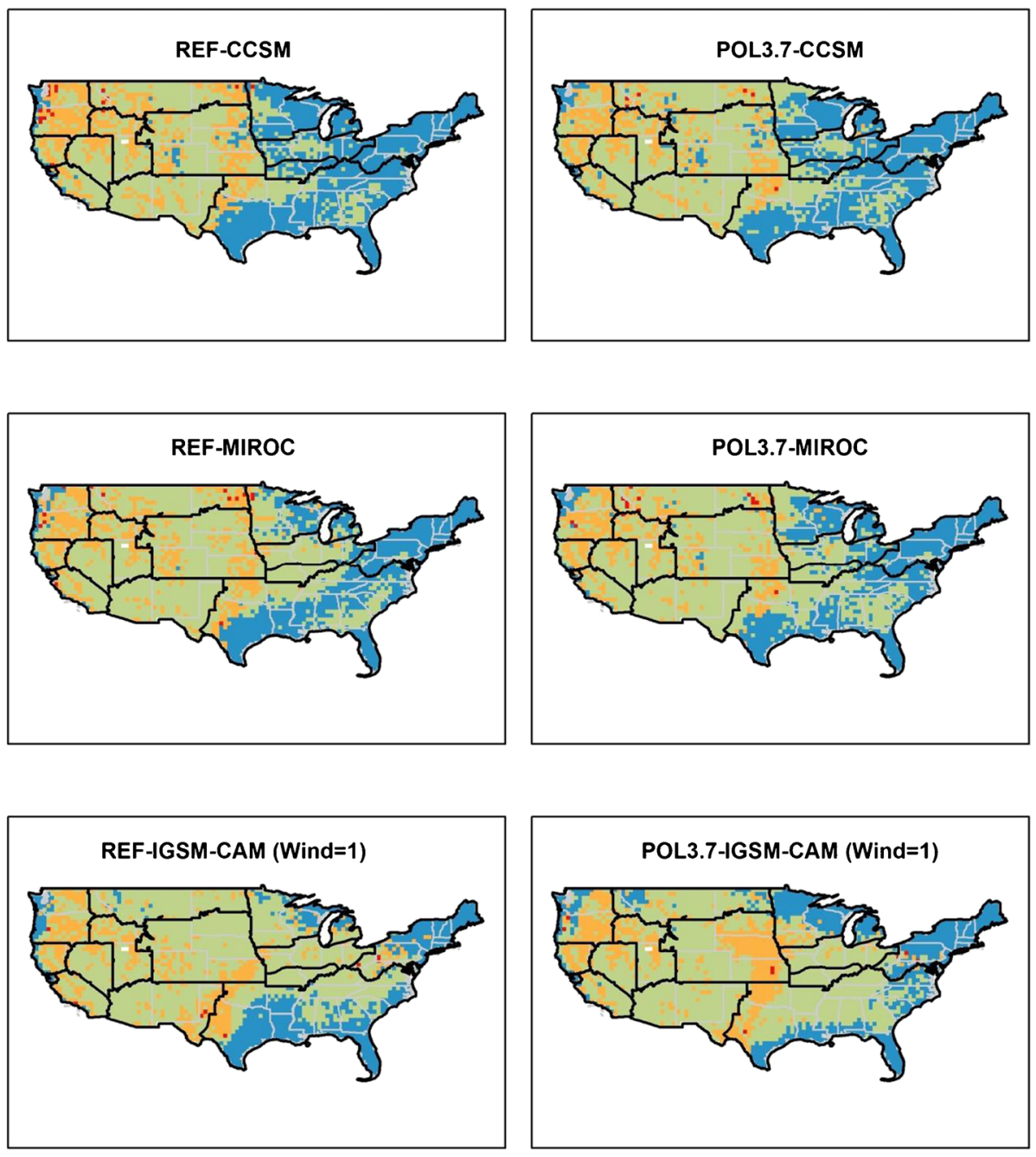

\section{Percentage of Cell Burned}

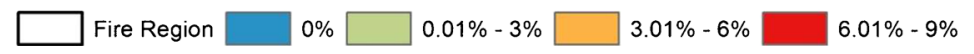

Fig. 2 Average percentage of MC1 cells burned over 30-year periods (note black lines denote fire regions)

in discounted monetized value of approximately $\$ 0.18$ trillion for CCSM and an increase in value of $\$ 3.53$ trillion (2005USD) for MIROC (Table 1).

The trajectory and timeline of national level terrestrial ecosystem carbon storage follow very different paths under the different models (Fig. 3). It is particularly striking that the largest carbon storage benefit from POL3.7 implementation accrues with MIROC despite its projecting an overall decline in carbon storage over the period, the only model where this occurs. 


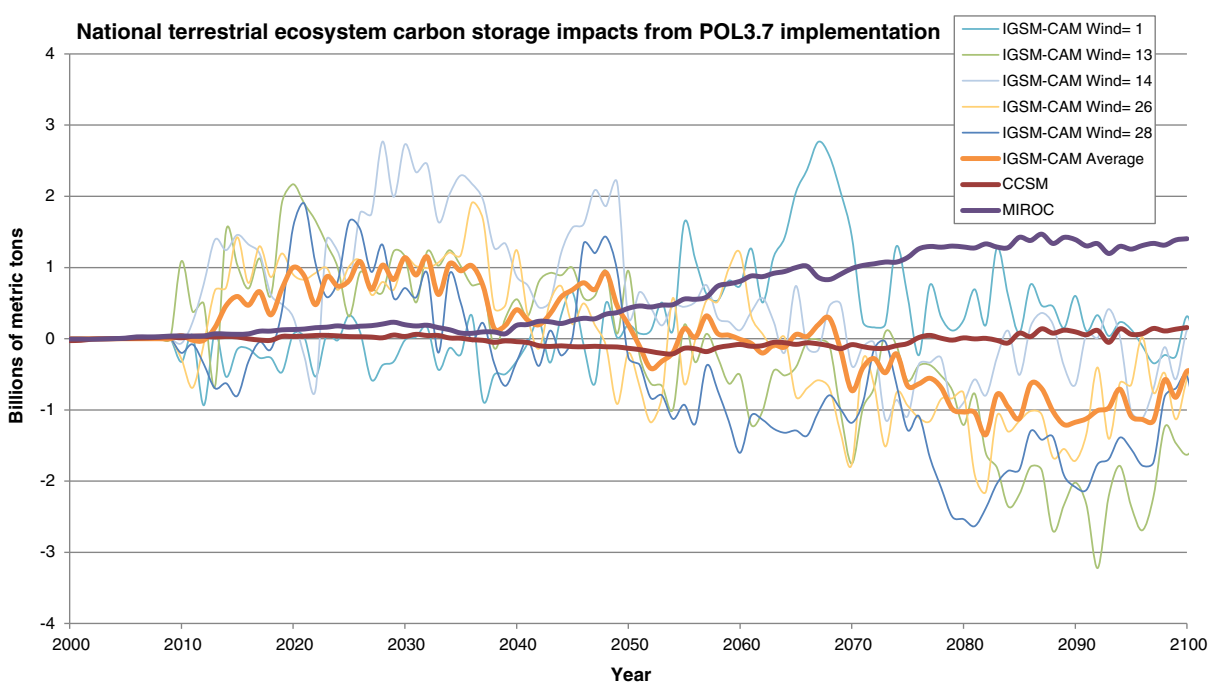

Fig. 3 National terrestrial ecosystem carbon storage benefits of POL3.7 implementation using MC1 projections from different models

The timing of periods where POL 3.7 implementation generates benefits, and the magnitude of those benefits, also varies by model. For most initializing conditions, the IGSM-CAM results show implementation benefits occurring in the first part of the evaluated period (i.e., 2001-2050) with a loss of carbon storage beginning in roughly 2050 that continues through 2100. However, the benefits from POL3.7 implementation for the IGSM-CAM (WIND=1) projections do not follow this pattern, with benefits accruing mainly in the 2050-2075 period (see Fig. 3), with loss of storage at the start and end of the 2001-2100 period.

With CCSM, small, relatively consistent annual losses in carbon storage begin in roughly 2040 and continue through 2100 (Fig. 3). In contrast, the MIROC results begin to consistently show benefits of implementing the POL3.7 controls starting in roughly 2040. These benefits then continue to increase in magnitude through year 2100 (Fig. 3, Table 1). The IGSM-CAM also shows much more inter-annual variability in national-level carbon storage than the two pattern-scaled projections (Fig. 3). Online Resource 2 describes the likely causes of these differences.

It is also interesting to note that while the net benefits accrued imply that the MIROC and CCSM model results bracket those of the IGSM-CAM, this only holds true for the cumulative results (Table 1). While the MIROC and CCSM results tend to produce fairly consistent increases and decreases in storage over time, at least from 2040 on, the IGSM-CAM paths shows much more inter-annual variability (Fig. 3).

Reviewing terrestrial ecosystem carbon storage dynamics by region provides further insights into national-level patterns (see Online Resource 12). As with wildfire, the results by region vary considerably over time across models (Table 1). Similarly, national results are largely driven by impacts from a small number (i.e., one to three) of regions. Specifically, across models, dynamics in the Southern Area and the Northern Rockies are important drivers of the national trend. However, for the IGSM-CAM results, the importance of these regions varies, with the Eastern Area and Rocky Mountain regions also playing a significant role at different points in time (see Online 
Table 1 POL3.7 impacts on carbon storage, valuation using the average SCC discounted at $3 \%$

\begin{tabular}{|c|c|c|c|c|c|c|}
\hline Decade & $\begin{array}{l}\text { IGSM-CAM } \\
(\mathrm{WIND}=1)\end{array}$ & $\begin{array}{l}\text { IGSM-CAM } \\
(\mathrm{WIND}=13)\end{array}$ & $\begin{array}{l}\text { IGSM-CAM } \\
(W I N D=14)\end{array}$ & $\begin{array}{l}\text { IGSM-CAM } \\
(\text { WIND }=26)\end{array}$ & $\begin{array}{l}\text { IGSM-CAM } \\
(\mathrm{WIND}=28)\end{array}$ & MIROC \\
\hline
\end{tabular}

\begin{tabular}{|c|c|c|c|c|c|c|c|}
\hline \multicolumn{8}{|c|}{ Change in terrestrial ecosystem carbon storage (POL3.7 - REF, billions of metric tons) } \\
\hline 2001-2010 & $(0.3)$ & 1.1 & $(0.1)$ & $(0.3)$ & $(0.2)$ & 0.2 & 0.1 \\
\hline $2011-2020$ & $(2.6)$ & 9.3 & 9.0 & 7.1 & $(1.1)$ & 0.8 & 0.2 \\
\hline 2021-2030 & $(1.3)$ & 10.9 & 13.4 & 8.8 & 11.1 & 1.8 & 0.3 \\
\hline $2031-2040$ & $(2.5)$ & 7.2 & 18.4 & 11.2 & 1.6 & 1.3 & 0.0 \\
\hline $2041-2050$ & 0.8 & 7.1 & 12.5 & 1.1 & 4.2 & 2.9 & (1.1) \\
\hline 2051-2060 & 6.3 & $(4.0)$ & 4.1 & 0.5 & $(9.1)$ & 5.9 & (1.5) \\
\hline $2061-2070$ & 17.6 & $(6.5)$ & 2.0 & $(5.6)$ & (11.4) & 9.2 & $(0.8)$ \\
\hline $2071-2080$ & 3.7 & $(5.5)$ & $(6.1)$ & $(8.9)$ & (12.9) & 11.8 & $(0.5)$ \\
\hline $2081-2090$ & 5.3 & (19.4) & $(2.3)$ & $(14.6)$ & (18.8) & 13.6 & 0.5 \\
\hline $2091-2100$ & 0.2 & $(21.1)$ & $(2.9)$ & (7.3) & (14.1) & 13.1 & 0.9 \\
\hline Total & 27.2 & $(21.0)$ & 48.1 & $(8.0)$ & $(50.9)$ & 60.5 & (1.9) \\
\hline $\begin{array}{l}\text { IGSM-CAM } \\
\text { average }\end{array}$ & $(0.9)$ & & & & & & \\
\hline SD & 39.2 & & & & & & \\
\hline
\end{tabular}

Discounted monetized values for projected changes in terrestrial ecosystem carbon storage (POL3.7 - REF, billions US\$ 2005 using the average SCC)

$\begin{array}{rlllllll}2001-2010 & (\$ 42) & \$ 141 & (\$ 8) & (\$ 37) & (\$ 26) & \$ 5 & \$ 2 \\ 2011-2020 & (\$ 333) & \$ 1,196 & \$ 1,169 & \$ 917 & (\$ 148) & \$ 104 & \$ 22 \\ 2021-2030 & (\$ 160) & \$ 1,323 & \$ 1,587 & \$ 1,059 & \$ 1,344 & \$ 215 & \$ 42 \\ 2031-2040 & (\$ 258) & \$ 784 & \$ 1,985 & \$ 1,202 & \$ 184 & \$ 135 & \$ 3 \\ 2041-2050 & \$ 77 & \$ 660 & \$ 1,155 & \$ 115 & \$ 373 & \$ 264 & (\$ 98) \\ 2051-2060 & \$ 489 & (\$ 316) & \$ 329 & \$ 15 & (\$ 714) & \$ 460 & (\$ 121) \\ 2061-2070 & \$ 1,152 & (\$ 433) & \$ 139 & (\$ 351) & (\$ 761) & \$ 611 & (\$ 56) \\ 2071-2080 & \$ 203 & (\$ 296) & (\$ 331) & (\$ 485) & (\$ 683) & \$ 644 & (\$ 28) \\ 2081-2090 & \$ 239 & (\$ 862) & (\$ 107) & (\$ 657) & (\$ 851) & \$ 609 & \$ 19 \\ 2091-2100 & \$ 11 & (\$ 778) & (\$ 102) & (\$ 269) & (\$ 522) & \$ 478 & \$ 33 \\ \text { Total } & \$ 1,377 & \$ 1,420 & \$ 5,815 & \$ 1,510 & (\$ 1,802) & \$ 3,525 & (\$ 180) \\ \text { IGSM-CAM } & \$ 1,664 & & & & & & \end{array}$

Totals may not sum due to rounding.

Resource 12). In the IGSM-CAM, it is striking that the POL3.7 carbon storage benefits shift from positive to negative in some of the regions (e.g., Northern Rockies and Southern Area) over the century.

We note that when focusing on long-term averages, critical underlying annual patterns and dynamics could be missed or misinterpreted. For example, when 30-year averages of ecosystem carbon storage benefits are examined for 2050 and 2080 (see Online Resource 13), the acceleration of benefit accumulation over time under both the MIROC and CCSM models is not evident (Online Resource 12). In addition, the IGSM-CAM averages shown in Online Resource 13 fail to capture the entire period over which significant benefits accrue for this model. 


\section{Discussion}

\subsection{Estimates of impacts and benefits of the GHG mitigation scenario}

Our national-scale analysis using the annual results produced by $\mathrm{MC} 1$ demonstrate that implementing the POL3.7 GHG emission controls would reduce the area burned by wildfire on the order of tens of millions of hectares in the U.S. over the 2001-2100 period. The sign and scale of this result is generally consistent regardless of the type of modeling approach used (i.e., GCM or pattern-scaled model) or the initializing conditions used for the IGSM-CAM. The discounted, monetized value of these reductions in burned area is on the order of billions of dollars in potentially avoided response costs for the period.

In contrast, our impact results for terrestrial ecosystem carbon storage are highly dependent upon the projected future climate. Results from both the pattern-scaled models (CCSM and MIROC) and the alternative initializing conditions for IGSM-CAM vary in sign (i.e., benefits or damages) with the relative units being billions to tens of billions of metric tons. Monetized, the cumulative (2001-2100) impact is valued in trillions of discounted dollars.

At a finer spatial scale, we find varying regional results. Generally, national results for wildfire and terrestrial ecosystem carbon storage appear driven by results from a limited number of regions. However, in these regions, depending on the time period, implementing the POL3.7 GHG emission controls can generate significant benefits or damages in any year.

Our analyses were also clearly influenced by the climate projection method. In short, the full GCM (IGSM-CAM) was designed to incorporate and reflect variability while the pattern scaling, which was employed to capture a wider range of GCM projections for precipitation, resulted in a smoothing out or muting of the original variability the model produces. This is true despite the fact that the pattern-scaled data were super-imposed on historical climate data, which incorporates historical climate variability. As a result, we believe it is important that the two approaches be seen not as direct substitutes but as alternatives or complements, based largely on a consideration of the research question of interest. If the timing and severity of the impacts of interest will be defined mainly by changes in future extreme conditions, use of results from a full GCM may be preferred because of the variability reflected. Use of patternscaled data in these cases may still be valuable, especially when investigating uncertainties in precipitation projections, but the effect of the pattern-scaling method on future variability and extremes will need to be recognized.

One can perhaps best observe the potential impact of utilizing a full GCM run versus pattern scaling in Fig. 3, which shows high variability in the IGSM-CAM but not MIROC or CCSM, though the average cumulative IGSM-CAM results are bounded by the pattern-scaled results. Similarly, IGSM-CAM projections produce abrupt changes in the sign and size of the impact of the POL3.7 scenario on acres burned by wildfires that are not present in the patternscaled models (see Online Resource 11). In comparing these results with those found in previous studies, Online Resource 10 explores the differences in acreage estimates across the literature. This online resource also examines the likely drivers of the large wildfire estimates reported in this paper that include (1) the analysis of all fire types and sizes on all vegetated, non-agriculture lands (i.e., public and private); (2) the interaction between the dynamic MC1 model and a "wet" GCM (the IGSM-CAM) with realistic representation of inter-annual and natural variability; (3) the estimation of burned acres out to 2100 , not just mid-century; (4) the use of a mechanistic vegetation model to dynamically simulate vegetation composition and distribution over time, an advantage over statistically based approaches; and (5) the analysis of divergent emission scenarios including a reference, instead of solely analyzing a GHG mitigation scenario. 
While our analysis shows, as expected, that GCM selection is important, it also highlights MC1's sensitivity to the climate variability provided by IGSM-CAM. In the context of policy analysis, decision-makers have multiple important, often countervailing considerations when deciding whether and how to incorporate these impacts:

- Capturing climate variability is crucial when using dynamic ecological models that are sensitive to temperature minima and maxima rather than annual means.

- Though the use of multiple models can be labor- and cost-intensive, multiple GCMs should be utilized where possible to capture the full range of potential impacts.

- Pattern scaling provides an efficient method for capturing a wider range of impacts, but this approach may mask important dynamics that would be revealed through the utilization of full GCM transients.

More generally, the magnitude of the discounted monetized impacts alone suggests that it is critical to integrate the sectoral impacts highlighted here into policy analyses. We believe the methods we developed and applied represent a reasonable and focused initial approach, but are hopeful that further research and analysis can improve and refine this work.

\subsection{Limitations}

Here we note important limitations to the methods we have developed and employed. The discussion is aimed to (1) improve understanding of some potential biases and gaps in the data we present, and (2) highlight areas for further research that would improve related future efforts.

\section{Wildfire and terrestrial ecosystem carbon storage modeling}

- We utilized a single DGVM. Utilizing more than one DGVM in future analyses would present a fuller range of the possible impacts.

- We did not consider limitations to plant migration. $\mathrm{MC1}$ does not assume dispersal limits for any species.

- Changes in pest dynamics are not considered. The exclusion of pests from MC1 and other DGVMs presents large uncertainties regarding the properties and processes that will shape future ecosystems.

- Ignition sources were assumed to be uniformly non-limiting. $\mathrm{MC1}$ assumes a fire will start once certain biotic and abiotic conditions are met. As ignition sources are more prevalent near urban and agricultural areas, this could mean there is an over-prediction of the number of fires occurring in remote areas. However, some research indicates that climate change could result in an increase in natural ignition sources, such as lightning (Price and Rind 1994), which might imply an under-prediction of future fires.

- Future shifts in land management are not addressed. A number of policies could be pursued that could affect carbon storage and wildfires. These potential changes (e.g., thinning, prescribed burns) were not modeled in this analysis.

- Potentially offsetting future carbon fluxes are not addressed. A policy that results in increased ecosystem carbon storage now could result in larger potential releases in the future. While this could affect future summaries of the physical impacts, which are undiscounted, any such flux would have a diminished monetized impact because of the impact of discounting on the present value SCC estimates. 


\section{Monetization methods}

- Many impacts are not captured. The current monetization approaches do not capture all of the impacts associated with changes in carbon storage in terrestrial ecosystems or in wildfires. For example, wildfire-driven health impacts from degraded ambient air quality are not captured, while the SCC does not account for all the important physical, ecological, and economic impacts of climate change recognized in the literature.

- Uncertainty in wildfire response costs. Future changes in insurance requirements, wildfire response policies, and resource availability could affect response costs but are not accounted for here.

- The long time horizons used for SCC estimates contribute to uncertainty. The SCC estimates for the years 2010 to 2050 embed calculations through the year 2300 . Extrapolating the SCC estimates to provide annual values for the 2051-2100 period introduces additional uncertainty to the monetized results for terrestrial ecosystem carbon storage. Inclusion of the extrapolated estimates is instructive, however, given the varying trends in carbon storage for the 2001-2100 period, and allows for consistency with the other analyses in the Climate Change Impacts and Risk Analysis (CIRA) framework.

\section{Conclusions}

Our analyses show terrestrial ecosystems and at least some of services they provide are likely to be significantly affected by different GHG emission trajectories, such as the mitigation scenario POL3.7, modeled here. However, the variability in our results, especially for terrestrial ecosystem carbon storage, also highlights the sensitivity of these impacts to the type of model inputs considered and the parameterization of the specific model. Further, our results highlight the importance of examining the complexity of where and when benefits accrue. Summarizing aggregated national results could mask critical annual dynamics and regional differences likely to be of interest to local populations, which can be important when considering policy development and implementation.

Our results also draw attention to the issue of climate projection methodology and GCM selection in conducting climate change impacts research. Despite our efforts to integrate information from multiple GCMs by applying pattern-scaled data to historical climate data, the full GCM transient showed much more inter-annual variability than either pattern-scaled model. Thus, when utilizing dynamic models sensitive to temperature or precipitation thresholds, methods used to project and analyze potential impacts should be chosen with consideration of the research question at hand. Our data suggest that climate variability may significantly affect estimates of future terrestrial ecosystem carbon storage and acreage burned by wildfire, a conclusion also recently found by others (e.g., USDA 2012). Advancing the understanding of how variability may change in the future, how it is modeled in climate projections, and the calibration of vegetation models for these changes are important focus areas for further research. Subsequent analyses that run the MC1 DGVM with output from additional GCM models (full and/or pattern scaled), while requiring large ensemble simulations that are both time- and computer-intensive, could better constrain the range of projected climate impacts and identify important sources of variation in observed results. 
Acknowledgments The authors wish to acknowledge the financial support of the U.S. Environmental Protection Agency's (EPA's) Climate Change Division (Contract EP-BPA-12-H-0024). The views expressed in this document are solely those of the authors, and do not necessarily reflect those of EPA.

Open Access This article is distributed under the terms of the Creative Commons Attribution License which permits any use, distribution, and reproduction in any medium, provided the original author(s) and the source are credited.

\section{References}

Bachelet D, Lenihan JM, Daly C, Neilson RP, Ojima DS, Parton WJ (2001) MC1: a dynamic vegetation model for estimating the distribution of vegetation and associated ecosystem fluxes of carbon, nutrients, and water, technical documentation. Version 1.0. General Technical Report PNW-GTR-508. June

Bachelet D, Neilson RP, Hickler T, Drapek RJ, Lenihan JM, Sykes MT, Smith B, Sitch S, Thonicke D (2003) Simulating past and future dynamics of natural ecosystems in the United States. Glob Biogeochem Cycles 17(2):1045. doi:10.1029/2001GB001508

Bachelet D, Neilson RP, Lenihan JM, Drapek RJ (2004) Regional differences in the carbon source-sink potential of natural vegetation in the U.S.A. Environ Manag 33:S23-S43

CBI (Conservation Biology Institute) (2011) Digital data sets. http://app.databasin.org/app/workspace/ workspaceHomePage.jsp. Accessed 7 April 2011

Daly C, Bachelet D, Lenihan JM, Parton W, Neilson RP, Ojima D (2000) Dynamic simulations of tree-grass interactions for global change studies. Ecol Appl 10:449-469

GACC (Geographic Area Coordination Centers) (2011) National GACC portal. http://gacc.nifc.gov/index.php. Accessed 2 March 2011

Lal R (2004) Soil carbon sequestration impacts on global climate change and food security. Science 304:16231627

Lenihan JM, Bachelet D, Drapek R, Neilson RP (2006) The response of vegetation distribution, ecosystem productivity, and fire in California to future climate scenarios simulated by the MC1 Dynamic Vegetation Model. California Climate Change Center, California Energy Commission

Lenihan JM, Bachelet D, Neilson RP, Drapek R (2008) Simulated response of coterminous United States ecosystems to climate change at different levels of fire suppression, $\mathrm{CO}_{2}$ emission rate, and growth response to $\mathrm{CO}_{2}$. Glob Planet Chang 4:16-25

Monier E, Scott JR, Sokolov AP, Forest CE, Schlosser CA (2013) An integrated assessment modelling framework for uncertainty studies in global and regional climate change: the MIT IGSM-CAM (version 1.0). Geosci Model Dev 6:2063-2085. doi:10.5194/gmd-6-2063-2013

Monier E, Gao X, Scott J, Sokolov A, Schlosser A (2014) A framework for modeling uncertainty in regional climate change. Clim Change. doi:10.1007/s10584-014-1112-5

National Interagency Fire Center (2013) Total wildland fires and acres (1960-2009). http://www.nifc.gov/ fireInfo/fireInfo_stats_totalFires.html. Accessed 14 August 2013 (note table covers through 2012)

National Research Council (2011) Climate stabilization targets: emissions, concentrations, and impacts over decades to millennia. National Academies Press, Washington

NWCG (National Wildfire Coordinating Group) (2011) Historical incident ICS-209 reports. http://fam.nwcg. gov/fam-web/hist_209/report_list_209. Accessed 1 April 2011

Oregon State University (2011) $\bar{M} \overline{1}$ dynamic vegetation model. http://www.fsl.orst.edu/dgvm/. Accessed 9 May 2012

Paltsev S, Monier E, Scott J, Sokolov A, Reilly J (2013) Integrated economic and climate projections for impact assessment. Clim Chang. doi:10.1007/s10584-013-0892-3

Price C, Rind D (1994) Climate change impacts on terrestrial ecosystems and forests in the United States. J Climatol 7:1484-1494

PRISM Climate Group (2007) Latest PRISM data. Oregon State University, parameter-elevation regressions on independent slopes model climate group. http://prism.oregonstate.edu. Accessed November 2011

Rogers B, Neilson R, Drapek R, Lenihan J, Wells J, Bachelet D, Law B (2011) Impacts of climate change on fire regimes and carbon stocks of the U.S. Pacific Northwest. J Geophys Res Biogeo 116:G03037

Shaw MR, Pendleton L, Cameron D, Morris B, Bratman G, Bachelet D, Klausmeyer K, MacKenzie J, Conklin D, Lenihan J, Haunreiter E, Daly C (2009) The impact of climate change on California's ecosystem services. CEC-500-2009-025-F. California Energy Commission, California Climate Change Center 
Spracklen DV, Mickley LJ, Logan JA, Hudman RC, Yevich R, Flannigan MD, Westerling AL (2009) Impact of climate change from 2000 to 2050 on wildfire activity and carbonaceous aerosol concentrations in the western United States. J Geophys Res 114, doi:10.1029/2008JD010966

U.S. DOL (U.S. Department of Labor) (2011) Consumer price index, all urban consumers (CPI-U) - U.S. City average, all items, 1982-84=100. ftp://ftp.bls.gov/pub/special.requests/cpi/cpiai.txt. Accessed 1 April 2011

U.S. EPA (U.S. Environmental Protection Agency) (2013) Annex 3.12. Methodology for estimating net carbon stock changes in forestry land remaining forest lands. In Inventory of US greenhouse gas emissions and sinks: 1990-2011. EPA 430-R-13-001

U.S. Interagency Working Group on Social Cost of Carbon (2013) Technical support document: technical update of the social cost of carbon for regulatory impact analysis under Executive Order 12866. http://www. whitehouse.gov/sites/default/files/omb/inforeg/social_cost_of_carbon_for_ria_2013_update.pdf. Accessed 5 August 2013

USDA (U.S. Department of Agriculture) (2012) Effects of climatic variability and change on forest ecosystems: A comprehensive science synthesis for the U.S. forest sector. In: Vose JM, Peterson DL, Patel-Weynand T (eds) Gen. Tech. Rep. PNW-GTR-870. U.S. Department of Agriculture, Forest Service, Pacific Northwest Research Station, Portland

Waldhoff S, Martinich J, Sarofim M, DeAngelo B, McFarland J, Jantarasami L, Shouse K, Crimmins A, Ohrel S, Li J (2014) Overview of the special issue: a multi-model framework to achieve consistent evaluation of climate change impacts in the United States. Clim Change, this issue 